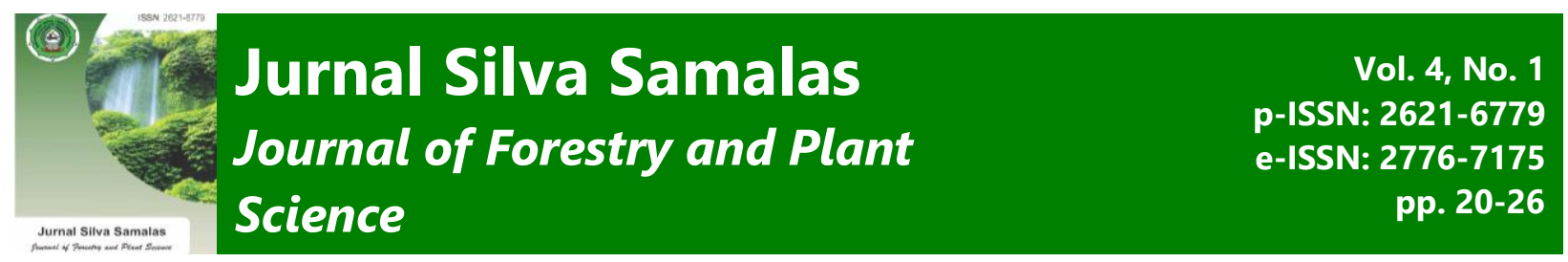

\title{
STUDI PENGELOLAAN HUTAN KEMASYARAKATAN (HKm) DI DESA SENGGIGI KECAMATAN BATU LAYAR KABUPATEN LOMBOK BARAT
}

\author{
M Fauzi*, Hafizah Nahlunnisa \\ Program Studi Kehutanan Universitas Pendidikan Mandalika, Jl Pemuda No.59A Dasan Agung, Mataram
}

\begin{abstract}
Community forest (HKm) is a state forest whose main use is intended to empower communities in and around forest areas. This study aims to determine the management in the form of plant composition and agroforestry systems in the forest area managed by the HKm Gapoktan Mertesari group in the Senggigi Village area, Batu Layar District. The method used is a land survey and interviews with the Mertesari Gapoktan group by taking respondents using a random sampling method. The data analysis used is descriptive analysis. The results showed that the composition of plants in the forest area managed by the HKm Gapoktan Mertesari group consisted of local wood species such as Ajan/Klicung, Rajumas, Klokos, Gaharu, Majagau which grew naturally. In addition, to enrich the diversity of plant species with woody plant species such as Sengon, Mahogany and MPTs such as Jackfruit, Cashew and Asam with the growth percentage reaching $80 \%$. The agroforestry pattern in this area is multiple cropping without any spacing because the forestry plants are densely packed.
\end{abstract}

Keywords: community forest (HKm), management, Gapoktan

\begin{abstract}
Abstrak
Hutan Kemasyarakatan $(\mathrm{HKm})$ adalah hutan negara yang pemanfaatan utamanya ditujukan untuk memberdayakan masyarakat di dalam dan sekitar kawasan hutan. Penelitian ini bertujuan untuk mengetahui pengelolaan berupa komposisi tanaman serta sistem agroforestri yang berada dikawasan hutan yang dikelola oleh kelompok HKm Gapoktan Mertesari di wilayah Desa Senggigi, Kecamatan Batu Layar. Metode yang digunakan adalah survei lahan dan wawancara terhadap kelompok Gapoktan Mertesari dengan pengambilan responden menggunakan metode random sampling. Analisis data yang digunakan adalah analisis deskriptif. Hasil penelitian menunjukkan bahwa Komposisi tanaman yang berada dikawasan hutan yang dikelola oleh kelompok HKm Gapoktan Mertesari terdiri dari jenis kayu lokal seperti Ajan/Klicung, Rajumas, Klokos, Gaharu, Majagau yang tumbuh secara alami. Selain itu, untuk memperkaya keanekaragaman jenis tanaman dengan jenis tanaman kayu-kayuan seperti Sengon, Mahoni dan MPTs seperti Nangka, Mente dan Asam dengan prosentase tumbuh mencapai $80 \%$. Pola agroforestry pada kawasan tersebut adalah multiple croping tanpa ada jarak tanam karena tanaman kehutanannya sudah rapat.
\end{abstract}

Kata Kunci: hutan kemasyarakatan (HKm), pengelolaan, Gapoktan

How to Cite: Fauzi, M. dan Nahlunnisa, H. (2021) 'Studi Pengelolaan Hutan Kemasyarakatan (HKm) di Desa Senggigi Kecamatan Batu Layar Kabupaten Lombok Barat', Jurnal Silva Samalas: Journal of Forestry and Plant Science, 4 (1), pp. $20-26$.

Copyright $\subset$ 2021, Fauzi dan Nahlunnisa This is an open-access article under the CC-BY-SA License. (c) (i) (?)

\section{PENDAHULUAN}

Peraturan Menteri Kehutanan no. P.37/MenhutII/2007 tentang hutan kemasyarakatan menyatakan bahwa hutan kemasyarakatan adalah adalah hutan negara yang pemanfaatan utamanya ditujukan untuk memberdayakan masyarakat setempat. Hutan Negara yang dimaksud yaitu hutan yang berada pada tanah yang tidak dibebani hak atas tanah. Kegiatan pengelolaan hutan 
kemasyarakatan dilakukan oleh masyarakat setempat yang dijadikan mitra oemerintah degan menggunakan areal kerja HKm sebagi kawasan yang dikelola dengan skema hak guna pakai dan bukan hak milik. Hal ini dilakukan untuk menghindari konflik yang terjadi di masyarakat dan diharapkan dapat melestarikan hutan serta meningkatkan ekonomi masyarakat. Hasil penelitian (Abdurrahim, 2015) menyebutkan bahwa konflik pengelolaan sumber daya alam di hutan NTB bersumber dari perebutan akses dan hak pengelolaan antara Pemerintah Provinsi Nusa Tenggara Barat dengan masyarakat lokal. Sehingga tujuan didirikannya hutan kemasyarakatan (HKm) adsalah untuk memberdayakan masyarakat di dalam dan sekitar kawasan hutan. Murbani (2006) menyatakan bahwa pemberdayaan masyarakat dilihat sebagai upaya meningkatkan kemampuan dan kemandirian masyarakat agar mereka menadapatkan manfaat sumberdaya hutan secara optimal dan adil melalui pengembangan kapasitas dan pemberian akses dalam rangka kesejahteraan masyarakat.

Kondisi pelaksanaan Hutan Kemasyarakatan (HKm) dapat diterapkan pada kawasan hutan lindung dan hutan produksi yang tidak dibebani hak atau izin. Pemanfaatan hasil hutan di kawasan tersebut menjadi sumber mata pencaharian masyarakat setempat. Hutan Kemasyarakatan (HKm) diperuntukkan bagi masyarakat miskin yang tinggal didalam dan sekitar kawasan hutan serta menggantungkan penghidupannya dari memanfaatkan sumberdaya hutan . Kelompok petani hutan, koperasi atau masyarakat diberikan hak pengusahaan hutan baik untuk tujuan produksi maupun perlindungan hutan (Moeliono et al., 2015). Izin usaha pemanfaatan pengelolaan Hutan Kemasyarakatan $(\mathrm{HKm})$ diberikan untuk jangka waktu 35 tahun dan 4 dapat diperpanjang sesuai dengan hasil evaluasi setiap 5 tahun. Pelaksanaan Hutan Kemasyarakatan (HKm) dapat dipilah dalam tiga (3) tingkatan pertama, penetapan yang dilakukan oleh pemerintah pusat (Kementerian Kehutanan), kedua perizinan yang dilakukan oleh pemerintah daerah (Bupati/Walikota/Gubernur); dan ketiga pengelolaan dilapangan yang dilakukan oleh kelompok masyarakat pemegang izin usaha pemanfaatan hutan kemasyarakatan (HKm) (Wiyono, 2006). Konsep dan program Hutan Kemasyarakatan $(\mathrm{HKm})$ pada era reformasi ini semakin populer terdengar seiring dengan terjadinya perubahan paradigma pembangunan kehutanan dari Hutan untuk Negara (Forestry for State) menjadi Hutan untuk Rakyat (Forestry for People). Perubahan paradigma tersebut dimaksudkan agar rakyat/ masyarakat dapat berpartisipasi aktif dalam pembangunan kehutanan, dan pada gilirannya masyarakat pula yang memanfaatkan hasil-hasil hutan tersebut dengan tanpa mengabaikan fungsi ekologis lingkungan dari hutan.

Konsep HKm telah dikembangkan secara nasional pada 22 propinsi dengan luas keseluruhan sekitar 448.217 Ha, yang terdiri dari areal usulan penetapan wilayah HKm (162. 112,91 Ha), areal pembangunan $\mathrm{HKm}(208327 \mathrm{Ha})$, areal kerja $(55.420 \mathrm{Ha})$ dan areal yang diberi ijin sementara (62.357 Ha). Total kelompok masyarakat yang terlibat pada kegiatan HKm adalah 519 kelompok (Media DAS, 2007). Provinsi Nusa Tenggara Barat (NTB) merupakan salah satu propinsi yang telah melaksanakan HKm. Beberapa praktek HKm yang ada di NTB antara lain HKm yang dikelola oleh Perum Perhutani sebagai lanjutan kegiatan HTI di Pulau Sumbawa, HKm Dinas Kehutanan Propinsi NTB, HKm Kelompok Mitra Pengaman Hutan (KMPH) Sesaot yang difasilitasi oleh LP3ES NTB, HKm di kawasan hutan Batukliang, Lombok Tengah yang difasilitasi oleh Dinas Kehutanan Kabupaten Lombok Tengah dan Dinas Kehutanan Propinsi NTB, serta pengembangan Hkm di Propinsi NTB bantuan OECF di Lombok Timur dan Lombok Barat (Nandini, 2013).

Program HKm di Propinsi NTB mulai dilaksanakan pada tahun 1994/1995 untuk pulau Sumbawa dan 1996/1997 untuk pulau lombok. Pelaksanaan program tersebut telah memberikan manfaat sosial ekonomi bagi masyarakat disekitar lokasi HKm, terutama petani peserta program Hutan Kemasyarakatan (HKm).Pembangunan kehutanan di Provinsi Nusa Tenggara Barat (NTB) sebagai bagian integral dari pembangunan daerah dituntut untuk meningkatkan peranannya dalam mewujudkan pengelolaan sumber daya hutan yang lestari untuk sebesar-besarnya kemakmuran 5 masyarakat. Tuntunan ini didasarkan pada adanya interaksi yang kuat antara masyarakat hutan dalam memenuhi kebutuhan hidupnya.Hal ini memberikan indikasi bahwa pembangunan kehutanan diwilayah ini mamiliki peran hutan dalam mencapai keuntungan ekonomi dan sosial yang maksimal. Dalam hal ini, pembangunan hutan perlu diarahkan untuk mendapatkan keuntungan/pendapatan yang maksimal dan mengupayakan maksimalisasi peran hutan pada aspek perlindungan,rehabilitasi dan perbaikan mutu lingkungan hidup.

Pelaksanaan program HKm di NTB yang telah berjalan selama kurang lebih 15 tahun telah nyata memberikan banyak kontribusi dalam mendukung kegiatan pembangunan daerah baik dari 
aspek sosial,ekonomi, ekologi dan kelembagaan. Berdasarkan hasil penelitian yang telah dilakukan selama ini oleh para pihak baik secara kelembagaan maupun perorangan, program HKm telah mampu meningkatkan kesejahteraan masyarakat yang ditunjukkan dengan terjadinya peningkatan pendapatan terhadap masyarakat yang memiliki hak kelola dalam bentuk IUPHK. Kontribusi terbesar pendapatan masyarakat dari lahan HKm berasal dari komoditi hasil hutan bukan kayu 13 (HHBK) berupa tanaman MPTS (Multi Purpose Tree Species), seperti Kemiri, Coklat, Kopi, Durian dll. Hasil Hutan Bukan Kayu (HHBK) menjadi sandaran para petani HKm. Selain dapat menjadi penyangga kawasan hutan, HHBK juga dapat sebagai sumber pendapatan bagi masyarakat dan penciptaan lapangan kerja (Anonim,2012).

Tujuan dari penelitian ini adalah untuk mengetahui komposisi tanaman yang berada dikawasan hutan yang dikelola oleh kelompok HKm Gapoktan Mertesari di wilayah Desa Senggigi, Kecamatan Batu Layar. Serta untuk mengetahui pola Agroforestry serta pengembangan Hutan Kemasyarakatan $(\mathrm{HKm})$ dalam melestarikan hutan dikawasan Desa Senggigi Kecamatan Batu Layar.

\section{METODE PELAKSANAAN}

\section{a. Alat dan Bahan}

Alat dan bahan yang digunakan dalam penelitian ini antara lain: Meteran, Tallysheet, Tape rekorder, Camera, Alat tulis menulis

\section{b. Rancangan Percobaan}

Penelitian ini merupakan jenis penelitian deskriptif kualitatif. Penelitian deskriptif berupaya mendeskripsikan data apa adanya dan menjelaskan data atau kejadian dengan kalimat-kalimat penjelasan secara kualitatif (Sugiyono, 2008). Metode yang digunakan dalam pengumpulan data ini adalah metode survey, dengan mengambil sample dari satu kelompok tani dengan menggunakan kuisioner sebagai alat pengumpul data pokok. Data yang dikumpulkan untuk penelitian ini terdiri dari : a) Data Primer adalah data yang berkaitan langsung dengan obyek penelitian di lapangan, diperoleh melalui pemberian quesioner, wawancara, pengamatan langsung di lapangan dan dokumentasi. b) Data Sekunder adalah data yang mendukung penelitian dan melengkapi data primer, diperoleh dari pihak - pihak terkait (Desa, Kelompok tani, Dinas/instansi terkait)

\section{c. Cara Kerja}

Prosedur pengumpulan data dilakukan dengan cara :

a) Observasi lapangan dapat dilakukan dengan peninjauan dan pengenalan lapangan untuk mengetahui keadaan umum lokasi penelitian

b) Wawancara, merupakan pertemuan dua orang untuk bertukar informasi dan ide melalui tanya jawab, sehingga dapat dikonstruksikan makna dalam topik tertentu (Sugiyono, 2008). Pada penelitian ini digunakan wawancara mendalam. Wawancara mendalam digunakan untuk memperdalam informasi yang dibutuhkan. Dalam penelitian ini, peneliti menentukan besarnya sample adalah $10 \%$ dari jumlah 191 orang responden sehingga jumlah responden adalah 20 orang. Sample berasal dari 4 kelompk tani yaitu kelompok Angen dengan jumlah 15 angggota sebanyak 44 KK diambil 5 orang, Kelompok Beriuk Pacu dengan jumlah anggota sebanyak 50 KK diambil 5 orang, kelompok Patuh Angen sebanyak $42 \mathrm{KK}$ diambil 5 orang dan kelompok briuk tinjal 55 orang diambil 5 orang. Penentuan jumlah petani respondent dilakukan secara " Random Sampling ".

c) Study pustaka dilakukan dengan mencari informasi dan masukan mengenai kondisi di lokasi penelitian

\section{d. Analisis Data}

Data yang dikumpulkan akan diolah dan disajikan dalam tabulasi, kemudian data tersebut dianalisis secara deskriptif. Data-data yang dianalisis berupa data :

1. Komposisi Tanaman

Komposisi tanaman terdiri atas tanaman kehutanan, tanaman pertanian, dan tanaman perkebunan. Komposisi tanaman diolah dalam bentuk tabulasi dan dianalisis secara deskriptif kualitatif untuk penjelasan dari tabulasi. Komposisi tanaman adalah susunan pengkombinasian antara tanaman kehutanan, tanaman pertanian, dan tanaman perkebunan. 
2.Pola tanam agroforestry

Agroforestry adalah bentuk atau sistem penggunaan lahan, dimana pemakai lahan dapat memperoleh hasil tanaman pangan atau tanaman agronomi lain, tanaman pakan ternak dan hasil kayu, secara simultan, serta dapat melestarikan sumberdaya lahan tersebut. Dalam sistem agroforestry ada beberapa pola tanam, diantaranya adalah bentuk pola tanam tiga strata, multistorey cropping, alley cropping, dan sebagainya (Sutidjo, 1986), diolah dalam bentuk tabulasi dan dianalisis secara deskriptif untuk penjelasan dari tabulasi.

\section{HASIL DAN PEMBAHASAN}

\section{a. Kondisi Umum Lokasi Penelitian}

Berdasarkan administratif kewilayahan, Desa Senggigi berada dalam wilayah Kecamatan Batulayar Kabupaten Lombok Barat. Adapun luas kawasan hutan di wilayah Desa Senggigi mencapai 871,7 Ha terdiri dari hutan lindung seluas 475,60 Ha dan hutan konservasi seluas 396,10 Ha. Secara umum, peruntukan lahan di Desa Senggigi disajikan dalam Tabel 1 berikut ini :

Tabel 1. Penggunaan Lahan di Desa Senggigi

\begin{tabular}{lll}
\hline No & Penggunaan lahan & Luas $(\mathrm{Ha})$ \\
\hline 1. & Sawah & 0 \\
2. & Pemukiman & $405,20 \mathrm{Ha} / \mathrm{m}^{2}$ \\
3. & Perkebunan & $383,030 \mathrm{Ha} / \mathrm{m}^{2}$ \\
4. & Fasilitas Umum & $0,5203 \mathrm{Ha} / \mathrm{m}^{2}$ \\
& $-\quad$ Perkantoran & $0,09 \mathrm{Ha} / \mathrm{m}^{2}$ \\
& $-\quad$ Bangunan sekolah & $0,110 \mathrm{Ha} / \mathrm{m}^{2}$ \\
& - Terminal & $0,1 \mathrm{Ha} / \mathrm{m}^{2}$ \\
& $-\quad$ Jalan & $0,2203 \mathrm{Ha} / \mathrm{km}^{2}$ \\
5. & Hutan & \\
& $-\quad$ Hutan lindung & $475,60 \mathrm{Ha} / \mathrm{m}^{2}$ \\
& $-\quad$ Hutan konservasi & $396,10 \mathrm{Ha} / \mathrm{m}^{2}$ \\
6. & Pekarangan & $37,28 \mathrm{Ha} / \mathrm{m}^{2}$ \\
7. & Perkantoran & $0,40 \mathrm{Ha} / \mathrm{m}^{2}$ \\
8. & Pantai & $6 \mathrm{Ha}$ \\
9. & Kawasan wisata & $354,3 \mathrm{Ha}$ \\
\hline
\end{tabular}

Secara umum, tanah di wilayah DAS Dodokan Sub DAS Meninting sebagian besar bahan maupun sifat-sifatnya dipengaruhi oleh aktifitas Gunung Rinjani karena berdasarkan kawasan hutan masuk dalam gugusan RTK 1. Rinjani. Jenis tanah terdiri dari litosol sebesar 179,06 Ha, dan mediteran coklat 46,94 Ha. Kondisi topografi HKm Senggigi secara umum memiliki topografi landai sampai berbukit. Keadaan topografi ini lebih dipengaruhi oleh pengaruh Gunung Rinjani.

Kondisi penutupan lahan di lokasi HKm Senggigi Kecamatan Batulayar Kabupaten Lombok Barat seluas $126 \mathrm{Ha}$ berada di kawasan hutan lindung Rinjani RTK-1 masuk dalam kategori jenis penutupan lahan adalah hutan lahan kering sekunder. Kondisi tutupan kawasan hutan sebelum tahun 1990-an cukup bagus terdiri dari jenis kayu lokal seperti Ajan/Klicung (Diosphyros sp.), rajumas, klokos, gaharu, majagau yang tumbuh secara alami. Selain itu, pengkaayaan tanaman ikut andil memperkaya keanekaragaman jenis tanaman dengan jenis tanaman kayu-kayuan seperti sengon, mahoni dan MPTs seperti nangka, mente dan asam dengan prosentase tumbuh mencapai $80 \%$ dan terjaga sampai sekarang. Sedangkan secara swadaya tanaman yang dikembangkan seperti Durian, melinjo, ceruring dan semusim seperti kacang-kacangan, cabe, kecipir, kacang panjang, kedelai,terong,tomat dan empon-empon. Secara umum kondisi tutupan vegetasi di areal kerja HKm cukup bagus kecuali di 2 blok yaitu beriuk pacu dan angen yang vegetasinya masih jarang dikarenakan lokasi yang miring, terjal sehingga permukaan tanah didominasi jenis bebatuan.

Masyarakat yang mendiami Desa Senggigi berdasarkan data Profil Desa Senggigi tahun 2010 berjumlah 3.674 jiwa atau 1.072 KK. 23 Dari jumlah tersebut perempuan desa Senggigi jumlahnya 
1.788 jiwa dibandingkan dengan kaum laki-laki sebanyak 1.886 jiwa. Hal ini menunjukkan jumlah kaum perempuan lebih sedikit dibandingkan kaum laki-laki. Selain itu, sebagian besar penduduk bekerja sebagai petani dan swasta di bidang perhotelan. Penduduk Desa Senggigi ada yang menjadi pedagang dan nelayan.

Karakteristik responden yang diwawancarai dalam penelitian ini adalah berdasarkan kategori umur tergolong produktif, artinya secara fisik maupun mental sudah siap menghasilkan barang dan jasa. Hal ini sesuai dengan pendapat (Tjiptoherijanto, 2001)yang menyatakan bahwa golongan umur produktif antara 15-65 tahun sudah dianggap mampu bekerja. Selain itu pada usia produktif peluang untuk mengembangkan usaha masih besar. Berdasarkan tingkat pendidikan paling tinggi sebesar $40 \%$ merupakan tamat SD sedangkan berdasarkan pekerjaan, hasil menunjukkan bahwa seluruh responden (petani HKm) yaitu sebanyak 20 orang (100\%) dari sampel yang diambil menganggap HKm sebagai pekerjaan pokok karena tempat tinggal yang dekat dengan hutan. Tetapi luas lahan garapan yang relative sempit 21 menyebabkan responden harus mencari tambahan penghasilan menjadi honor daerah, peternak lebah, security, tukang bangunan, pengembala sapi, pembuat gula aren.

\section{KESIMPULAN}

1. Komposisi tanaman yang berada dikawasan hutan yang dikelola oleh kelompok HKm Gapoktan Mertesari terdiri dari jenis kayu lokal seperti Ajan/Klicung (Diospyros sp.), Rajumas, Klokos, Gaharu, Majagau yang tumbuh secara alami. Selain itu, untuk memperkaya keanekaragaman jenis tanaman dengan jenis tanaman kayu-kayuan seperti Sengon, Mahoni dan MPTs seperti Nangka, Mente dan Asam.

2. Pola agroforestry pada kawasan tersebut adalah multiple croping tanpa ada jarak tanam karena tanaman kehutanannya sudah rapat sedangkan pengembangan yang dilakukan adalah membuat blok perlindungan dan blok budidaya, Mengefektifkan awigawig kelompok dan kelompok pengamanan hutan, Membuat pipa saluran air dari sumber mata air, Penanaman bambu di bantaran kali

\section{SARAN}

Perlunya fasilitas yang memadai dari pemerintah agar untuk pengelolaan hutan kemasyarakatan (HKm) dapat dikelola dengan sebaik-baiknya

\section{UCAPAN TERIMAKASIH}

Saya ucapkan terima kasih untuk para responden yang telah mndukung dan bekerja sama selama penelitian ini berlangsung khususnya untuk anggota Gapoktan Mekarsari.

\section{DAFTAR PUSTAKA}

Abdurrahim, A. Y. (2015) 'Community forest (Hkm) collaborative scheme as a solution to conflict management of Sesaot Forest, West Lombok', Sodality: Jurnal of Rural Sociology, 03(03), pp. 91-100.

Marpaung, S. et al. (2014) 'Inventarisasi Tanaman MPTS ( Multy Purpose Tree Species ) Di Daerah Tangkapan Air Danau Toba Provinsi Sumatera Utara ( MPTS plant inventory in the catchment area of Toba Lake at North Sumatera Province )', pp. 1-5.

Media DAS. (2007). Perubahan Paradigma Pembangunan Kehutanan : Kerjasama Pusat dan Daerah Sangat Diperlukan. Edisi 07/Tahun I/Desember 2007. Jakarta.

Moeliono M., Mulyana A., Adnan H., Yuliani EL., Manalu P., \& Balang. (2015). Ijin Saja Tidak Cukup: Belajar dari Hutan Kemasyarakatan (HKM) di Bulukumba.Bogor: Brief.

Murbani. (2006). Kasubdin Kehutanan. Dinas Kehutanan dan Perkebunan Kabupaten Gunung Kidul. Yogyakarta.

Nahlunnisa, H., Zuhud, E. A. and Prasetyo, L. B. (2016) 'Penyebaran Spasial Keanekaragaman Tumbuhan Pangan Dan Obat Di Kampung Nyungcung, Desa Malasari, Kecamatan Nanggung, Bogor', Media Konservasi, 20(3), pp. 187-196. doi: 10.29243/medkon.20.3.

Nandini, R. (2013) 'Evaluasi Pengelolaan Hutan Kemasyarakatan (Hkm) Pada Hutan Produksi Dan Hutan Lindung Di Pulau Lombok', Jurnal Penelitian Hutan Tanaman, 10(1), pp. 43-55. doi: 10.20886/jpht.2013.10.1.43-55.

Peraturan Menteri Kehutanan nomor P.37/MenhutII/2007 tentang Hutan Kemasyarakatan tahun 2007 
Sugiyono. (2008). Metode Penelitian Kuantitatif Kualitatif dan R\&D. Bandung: Alfabeta

Sutidjo.(1986). Pengantar Sistem Produksi Tanaman Agronomi. Bogor: Diktat Kuliah Jurusan BDP, IPB,

Tjiptoherijanto, P. (2001) 'Proyeksi Penduduk, Angkatan Kerja, Tenaga Kerja, dan Peran Serikat Pekerja dalam Peningkatan Kesejahteraan Prijono', Majalah Perencanaan Pembangunan, (23), pp. $1-10$.

Wiyono. (2006). Peran Desa Dalam Hutan Kemasyarakatan. Yogyakarta:Yayasan SHOREA. 